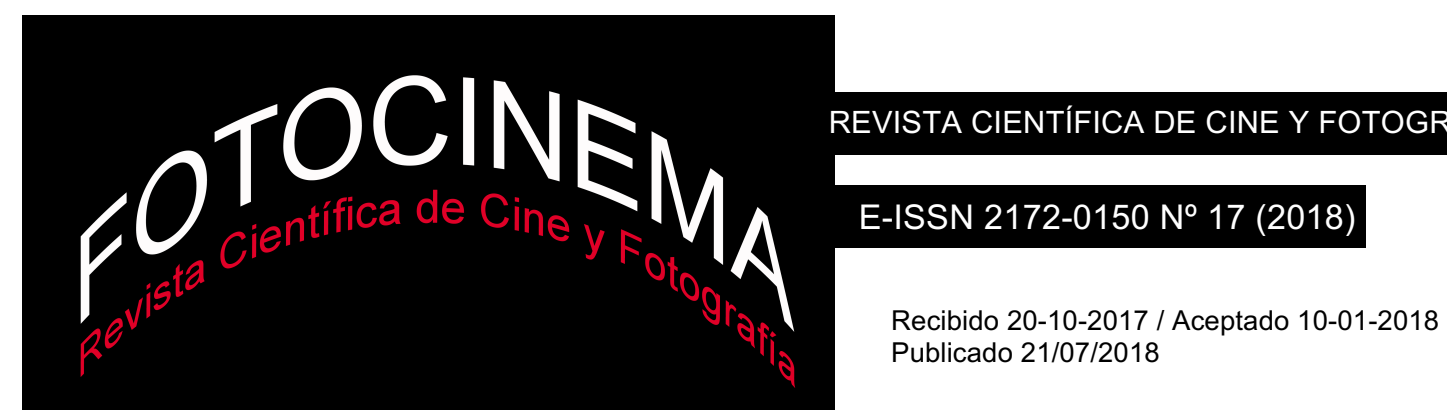

\title{
La percepción del cortometraje por los profesionales del cine español
}

\section{The perception of short films by spanish film professionals}

\author{
Alejandro de Vega de Unceta \\ Universidad Complutense, Madrid \\ alejandrodevega@ucm.es
}

\begin{abstract}
Resumen:
El cortometraje en España ha sido y es, a menudo, olvidado o relegado a un segundo plano frente a otros géneros y formatos de ficción audiovisual, como son los largometrajes o las series de televisión tanto por el público generalista como por la investigación académica. El presente trabajo pretende contribuir a avanzar en este conocimiento científico del cortometraje y, para ello, proponemos una investigación cualitativa, mediante entrevistas en profundidad, para comprender la percepción del cortometraje por parte de profesionales del cine español. Para el análisis se ha escogido a creadores (directores y guionistas) en activo en el mundo del cortometraje y con una experiencia contrastada en el largometraje. Nuestro avance de resultados permite afirmar que la industria del cortometraje es inexistente en España, lo que produce una desprofesionalización de los equipos de rodaje. También hemos comprobado que las motivaciones que mueven a los creadores a realizar cortometrajes han evolucionado con el tiempo. La distribución de los cortometrajes, que no tienen una ambición comercial, convierte esta forma expresiva en una forma de hacer cine con una libertad creativa total.
\end{abstract}

\begin{abstract}
:
Short films in Spain, are and have often been considered by the general public and by experts, second after other audiovisual genres such as log films or television series. This work aims to advance on academic knowledge of Short films. This was done through qualitative research by interviews in order to understand the perception of short films by professionals of Spanish cinema. For the analysis, creatives with experience in the field have been chosen. We have interviewed them deeply to acknowledge their opinions on this audiovisual genre at a production, exhibition, and distribution level to know their motivations as creatives and the formal and creative relations with long films. Our advance in the results allows us to affirm that the industry of short film does not exist in slain, which leads to a non-professional crew in the shootings. We have seen how the motivations that push creatives have evolved with time. The distribution of short films that does not have any commercial ambitions allows the art form to have complete creative freedom.
\end{abstract}

Palabras clave:

cine; percepción; cortometrajes; largometrajes.

Keywords:

Cinema; Perception; Short Movies; Movies. 


\section{Introducción}

El presente trabajo pretende ahondar en la percepción que tienen los creadores consagrados de la industria del cine en España acerca de los cortometrajes, su relación con los largometrajes, la industria cinematográfica, la situación actual y las propiedades creativas propias de esta forma de expresión. Utilizaremos a partir de ahora el término “creadores” para referirnos a los guionistas o directores de largometrajes que en la actualidad siguen realizando cortometrajes. La razón es que, como expondremos más adelante, de ellos surge la iniciativa de realizar los cortometrajes frente a la iniciativa que podría tener un productor de largometrajes.

El cortometraje en España es una “industria dentro de la industria”. El cine español genera más de 68.0oo puestos de trabajo al año, según el Anuario de Estadísticas Culturales ${ }^{1}$ que desarrolla el Ministerio de Cultura, y es reconocido en el Boletín Oficial del Estado (“BOE” en adelante) y beneficiado a través de una serie de ayudas que conceden anualmente a distribución y a producción de cortometrajes ${ }^{2}$. También es conocido, tal y como indica Deltell (2006) como un paso inevitable en la formación de todos los trabajadores de la industria del largometraje a través de las escuelas de cine y sus prácticas formativas con los "cortos"3. Conviene pues señalar las diferencias entre un largometraje y un cortometraje, ya que no debemos caer en la reducción de que los cortometrajes son solo películas de menor duración. Basándonos en las evidencias teóricas analizadas, comprobaremos si la población objeto de estudio valora el cortometraje como una forma expresiva independiente, con sus reglas y sus propios circuitos de exhibición, y que difiere de éste como

\footnotetext{
1 Índice del Anuario de Estadísticas Culturales: http://www.mecd.gob.es/servicios-alciudadano-mecd/estadisticas/cultura/mc/naec/portada.html Fecha de consulta: 1 de Junio de 2016

${ }^{2}$ Las ayudas a cortometrajes se conceden anualmente y se pueden consultar en la web del Ministerio de Educación, Cultura y Deporte:

http://www.mecd.gob.es/servicios-al-ciudadano-mecd/catalogo/cultura/becas-ayudas-ysubvenciones/ayudas-y-subvenciones/cine.html Fecha de consulta: 01 de Junio de 2016 3 Se utilizaran indistintamente, a partir de ahora, las expresiones cortometraje y "corto" por tratarse de un coloquialismo altamente extendido en el mundo profesional.
} 
difieren de los largometrajes, los spots publicitarios o los programas de televisión.

Los cortometrajes no tienen una garantía comercial. Simplemente, la inversión realizada en un cortometraje es imposible de recuperar salvo en muy contadas ocasiones, por ejemplo en el caso de Porque hay cosas que nunca se olvidan de Lucas Figueroa que ostenta el premio Guiness al cortometraje más premiado de la historia4. Quizá por ello la percepción general de los cortos es la de "plataforma de lanzamiento" para directores en ciernes. Sin embargo, son varios los casos de realizadores y escritores consagrados que vuelven a realizar cortometrajes a pesar de no tener esa necesidad de darse a conocer. En esta investigación queremos conocer la percepción de los creadores ya consolidados en el mundo del largometraje para arrojar luz sobre cuestiones como la situación del cortometraje a nivel de distribución, de exhibición, o incluso de creación artística.

\section{El cortometraje como forma expresiva independiente}

Según el BOE (29 de diciembre de 2007), un cortometraje sería "la película cinematográfica que tenga una duración inferior a sesenta minutos”. Desde este punto de vista, la única diferencia entre un largometraje y un cortometraje sería la duración. Es decir, si existe cortometraje es porque existe largometraje. Sin embargo, veremos que las diferencias entre uno y otro son mayores que sus similitudes.

Una de las primeras diferencias entre el cortometraje y el largometraje es el coste de producción, mucho menor en el de un cortometraje, salvo en contadas ocasiones. El coste medio de una película española se sitúa en torno a los 2.600.000 euros según el Instituto de Cinematografía y las Artes Audiovisuales, ("ICAA" en adelante), mientras que el coste medio de un cortometraje se sitúa en torno a los 25.000 euros (Calero, 2002, p.20),

\footnotetext{
4 Premio Guiness al cortometraje más premiado de la historia: Porque hay cosas que nunca se olvidan de Lucas Figueroa (2008): http://www.imdb.com/title/tt1292572/board/nest/177229614?ref =tt bd _1 Fecha de consulta: 1 de Junio de 2016
} 
aunque aquí solo se reconocen los cortometrajes con subvención gubernamental. Por el reducido coste del cortometraje frente al largometraje, los directores pueden tener una mayor libertad creativa y las posibilidades expresivas de un cortometraje son mayores. Estas diferencias expresivas se dan en todos los campos (narrativa, guion, dirección, etc.) por una razón: en pocos minutos el corto tiene que enganchar al espectador (Delgado, 2003, p. 13).

En el caso del cortometraje nos encontramos a nivel narrativo, según Alessandra Amitrano, con una modalidad expresiva cuya forma mantiene una estrecha relación con el argumento que la ha determinado. La tensión característica del lenguaje de los cortometrajes responde, sobre todo, a criterios de orden temporal; casi todos los elementos que aparecen son esenciales, y al servicio de esa esencialidad se dispone toda la estructura del film. El hecho de que un cortometraje desarrolle su función narrativa en el interior de módulos temporales limitados respecto a los de la narración clásica comporta la asimilación de formas expresivas radicalmente distintas de las utilizadas en la realización de un largometraje. El estilo de un cortometraje nace, ante todo, en función de la noción "tiempo". Una narración breve implica, por fuerza, la adopción de módulos estilísticos diferentes respecto a los que se adoptarían si se tratase de una narración larga. Pero por otro lado, las listas de recopilación del ICAA, por ejemplo, donde se indican las cifras específicas de las subvenciones concedidas a los cortos cada año, muestran la evidencia de una clara predilección por aquellos cortometrajes cuyas estructuras compositivas no difieren mucho de las de los largometrajes (Amitrano, 1998). No obstante, el gran número de cortos realizados cada año, se considerarán exclusivamente determinados trabajos cuyo lenguaje responda a criterios que sirvan para demostrar la existencia de obras autónomas, con una expresividad propia y original, independiente del largometraje.

De todo esto descubrimos que a nivel teórico el cortometraje difiere del largometraje no solo en su duración sino también en su estructura interna, en su forma de ser concebido y ejecutado, en sus medios de producción, en la 
distribución y en la exhibición. En definitiva, son medios expresivos similares que se mantienen en extremos opuestos del espectro comercial.

\section{El cortometraje en España}

\subsection{El cortometraje en España: de la "necesidad" a la "obligatoriedad"}

Comparando la situación actual del cortometraje en España nos encontramos con un desarrollo histórico único, debido a las transformaciones del sistema político español que han llevado a una evolución diferente del cortometraje respecto a otros países5. En España, desde los inicios del cine hasta bien entrados los años 80, la realización y proyección de cortometrajes ha sido una cuestión obligatoria, tal y como veremos en este epígrafe.

Con la invención del cinematógrafo por los hermanos Lumière y su posterior popularización en todo el mundo comienza la producción de películas y su exhibición pública. Comienza, precisamente, con la realización de cortometrajes. Estas limitaciones técnicas son la primera muestra de que la realización de cortometrajes no podía ser, a nivel de objetivos, la misma que ahora. En ese momento la realización de cortometrajes era obligatoria ya que los chasis de las cámaras solo podían albergar un número muy limitado de metros con los que grabar unos pocos segundos de imagen. Así pues, "hasta la generalización del largometraje en los años 20, todo el cine que se hace es corto" (Belchí, 1996, p. 13).

Con las mejoras técnicas de los cinematógrafos, las bobinas podían albergar más metros de película y, por tanto, ofrecer una mayor duración en las películas. La mayoría de las veces, durante el primer periodo del cine, estos cortometrajes se ofrecían en un programa junto a espectáculos de circo o de vodevil (Fernández, 1997). Es decir, que ya en ese momento la corta duración de las películas no era suficiente para satisfacer las necesidades del público, el cual quería ocupar más tiempo con los espectáculos a los que asistía. Esta

5 Decidimos no ahondar en esta situación ya que nos aleja de los objetivos de esta investigación. Para más información se puede consultar el libro de Román Gubern (2014). 
característica resulta clave para entender la perspectiva industrial actual del cortometraje frente al largometraje y cómo el primero ha perdido la batalla frente al segundo ya desde el comienzo del cine.

Con la aparición de la Segunda República comienza una época de protección constante del cortometraje por parte del Estado. Una situación que se sigue manteniendo hoy en día y que propicia una de las mayores paradojas del cortometraje español durante este periodo (podríamos decir que también durante toda su historia).

La distancia entre su reconocimiento y producción legislativos y sus condiciones reales de subsistencia. Sólo dos años después de acabada la Guerra Civil se establecen las primeras medidas proteccionistas de fomento en las que se incluye el cortometraje. Así, en La Orden del Ministerio de Industria y Comercio de 10 de diciembre de 1941 se estipulaba la obligatoriedad de exhibir cortometrajes españoles en todas las sesiones. (...) El sector del cortometraje no variará sustancialmente hasta bien entrada la década de los años 6o. (Tranche, 1996, pp. 80-85)

Con los cambios sociales y políticos de los años 70 asistimos al renacimiento del cortometraje de ficción en España. Sólo, a partir de 1970, el cortometraje de ficción comienza a aflorar, al margen de la producción oficial (cine, TVE, NO-DO), como "exóticas manifestaciones de una burguesía ilustrada (los dos focos principales radican en Barcelona y Madrid) o de jóvenes intelectuales con inquietudes sociales o estéticas, y que, por razones obvias, nacerá sin pretensión alguna de alcanzar espacios de difusión más allá de los reducidos cenáculos cinéfilos de los cine-clubes" (Barroso, 1996, p. 276). Esta falta de pretensiones comerciales es un estigma que se mantiene influido por los problemas de distribución y, sobre todo, exhibición que sufre el cortometraje fuera de los circuitos de festivales.

En 1976 se abolía en España la obligatoriedad de proyectar el NO-DO en las salas, aunque seguía siendo obligatoria la proyección de un cortometraje antes de los pases de las películas. De este modo cambiaba el panorama de los cortometrajes. Las salas compraban los cortometrajes "al peso" según la duración que necesitasen para rellenar la programación. De esta manera se 
sustituía la proyección del NO-DO por la de cortometrajes realizados exclusivamente con el fin de lograr una subvención estatal, cuyas concesiones se daban a todos los cortometrajes que solicitasen la financiación, sin tener en cuenta la calidad, la duración o los costes. Esto produjo en los cortometrajes una drástica bajada en su calidad convirtiéndose la mayoría de las veces en decididamente mala. De este modo, el motivo de la imposición estatal del pase de cortos reforzaba la actitud de escepticismo del público (Amitrano, 1998).

La obligatoriedad de estas proyecciones, sumada a la baja calidad de los cortometrajes, producía en el espectador un desprecio hacia "el corto". El fin de esta obligatoriedad hizo que se mejorase notablemente la calidad de los cortos, ya que las subvenciones concedidas pasaban por un criterio de calidad previo (Real Decreto 3304/1983); criterio que sigue conservándose para las subvenciones del ICAA.

\subsection{Situación actual del cortometraje en España}

A pesar de la gran repercusión internacional que tiene el cine cortometraje español, la tendencia general para los creadores es la de abandonar la realización de cortometrajes una vez consiguen un cierto prestigio y pueden realizar, de una forma relativamente constante, largometrajes. Pero teniendo en cuenta que, según hemos planteado inicialmente, los largometrajes y los cortometrajes son formas expresivas diferentes como lo pueden ser las series de televisión o los spots publicitarios, ¿por qué los directores abandonan la realización de cortometrajes, convirtiéndose estos en una plataforma de aprendizaje o una forma de darse a conocer?

Las dificultades de exhibición y financiación podrían ser los principales problemas. Por un lado, es muy difícil encontrar canales de exhibición que garanticen solidez en el sector. Esto se debe en parte a que el público no está acostumbrado a las obras menores de una hora de duración, y por ello los cortometrajes tienen una "falta de correspondencia con el modelo temporal canónico" (Amitrano, 1998). Esto ya se daba desde el principio del 
cinematógrafo y para compensar esta falta de duración existen los festivales de cortometrajes que agrupan estos para formar una sesión más completa.

El sector, a través de las diferentes leyes (1980, 1983, 20076), ampara y regula las ayudas oficiales para la realización de cortometrajes. Sin embargo, no se protege o ayuda su distribución o su proyección en televisiones, como sí se hace con el largometraje. Es un hecho el bajo o nulo conocimiento que el ciudadano español tiene de los cortometrajes que se producen anualmente (Fernández, 2015, p.77).

Los cortometrajes han dejado de emitirse tanto en las salas de cine como en la televisión. Aunque han existido programas dedicados exclusivamente al cortometraje (entre los que cabe destacar "Cortometraje", "La 2 en corto", o hasta 2013 "Somos cortos", todos ellos emitidos en La 2 de Televisión Española, siendo esta una televisión pública), actualmente no existe una programación en televisión para este tipo de cine. Estos programas han tenido un carácter más o menos fugaz (Barroso, 1996, p.263). El propio Canal+ que era el canal de exhibición de cortometrajes por excelencia durante muchos años ya sólo lo hace a través de su página web (a través de su plataforma en Movistar+). Y a pesar de todas estas dificultades, aparentemente insalvables, si contamos todos los cortometrajes sin ayudas oficiales que son distribuidos y proyectados en España, se producen más de un millar de cortos cada año (Fernández, 2015, p.73).

También, como decíamos, se ha abandonado su difusión en salas, que debería ser su lugar natural, igual que para los largometrajes. El tiempo del que antes gozaban los cortometrajes ahora se dedica a la publicidad y a los trailers de los próximos estrenos. Esto revierte solo en beneficios para las salas por el dinero recibido por la publicidad y para los largometrajes cuyos estrenos quedan reforzados con estos anuncios, apartando así los cortometrajes del lugar que les debería corresponder en las salas. De esta manera se afianzan los largometrajes y se expulsan a los cortometrajes de los cines. Los directores de cortometrajes no tienen pantallas donde exhibir sus

${ }^{6}$ Ley 3/1980, de 10 de enero. Real Decreto 3304/1983, de 28 de diciembre. Ley 55/2007, de 28 de diciembre. 
obras y los festivales no sirven para garantizar su supervivencia, aunque el esfuerzo institucional se centre en la presencia de las obras en dichos eventos nacionales e internacionales, y se obtengan importantes premios internacionales (Fernández, 2015).

Si descartamos la programación televisiva (y por tanto la posibilidad de una remuneración económica) y la programación en salas, abandonada hace años, y los festivales de cine (cuyos premios no aseguran la supervivencia de unos cortometrajes en su inmensa mayoría más costosos), cabe preguntarse: ¿para qué se realizan estos cortometrajes? ¿Qué percepción tienen estos autores de la realización de cortometrajes?

\subsection{De los directores consagrados y el cortometraje}

En los años 90 se produce una crisis en el mundo del cortometraje atribuida por Llorca (citado por Amitrano, 1998) a un abandono de la realización de cortometrajes por los directores que empiezan a hacer largometrajes. También para Jaime Barroso (1996) resulta "indiscutible que es ese [el aprendizaje del oficio] y no otro el ánimo que alienta en la mayoría de los cortometrajes y sus autores”.

Los medios técnicos que utilizan el cortometraje y el largometraje son idénticos. "Es raro encontrar a un director o realizador que no haya empezado rodando cortos. [...] No hay mejor escuela que la de saludar aciertos y enmendar fallos que rodar, rodar y rodar estas películas” (Delgado, 2003, p. 11). Se establece así el cortometraje como una suerte de escuela para aprender el oficio de cineasta. Esta forma de narración audiovisual supone el escalón previo y necesario para que alguien que aspire a la dirección de un largometraje cinematográfico en España.

Sin embargo, podemos ver cómo en los últimos años algunos directores y guionistas ya consagrados en la industria vuelven al formato corto, como son Gracia Querejeta, Javier Fesser, Borja Cobeaga, Nacho Vigalondo, etc., consiguiendo importantes premios nacionales e internacionales7. Por ello

7 Estos perfiles completos se pueden consultar en la base de datos Internet Movie Data Base
(IMDB): Gracia Querejeta: http://www.imdb.com/name/nmo703265/?ref =fn al nm 1; 
uno de los principales objetivos de esta investigación será la de conocer las motivaciones de estos directores para regresar al cortometraje a pesar de, como hemos visto, todas las dificultades que ello conlleva.

Como vemos, ninguna de las propuestas anteriores hace referencia a nuestro problema de investigación: la percepción del cortometraje a nivel de industria, creación, motivación y situación actual, por los profesionales cinematográficos consagrados en España. A nivel de percepción, aunque en este caso respecto al largometraje, podemos encontrar un estudio como el que editó la Entidad de Gestión de Derechos de los Productores Audiovisuales (en adelante Egeda) en 2009 sobre la percepción de los largometrajes por la sociedad española (Egeda, 2009), que si bien es ejemplar en cuanto a su novedosa propuesta, no ofrece ninguna reflexión sobre los motivos y orígenes de esa percepción por parte del público que podamos señalar como antecedente para nuestro trabajo. Ese estudio, además, no hace mención alguna a la situación de los cortometrajes y, siendo una forma expresiva propia y diferente de la del largometraje, debe ser estudiado de forma independiente. En caso contrario seguiremos incurriendo en el mismo error: dejar de lado los cortometrajes y lanzarlos al olvido, cuando son los beneficiarios de subvenciones, los que generan cientos de puestos de trabajo, los que reciben premios internacionales y los que se olvidan injustamente en las bibliografías.

\section{Objetivos y metodología}

La presente investigación se centra en el objetivo general de conocer la percepción del cortometraje por los directores y guionistas españoles. Según los informes de la Comunidad de Madrid ${ }^{8}$, el 50\% de los creadores de cortometrajes acaban siendo también los productores de sus obras. Si se ha

Javier Fesser: http://www.imdb.com/name/nmo275250/?ref_=fn_al_nm_1; Borja Cobeaga: http://www.imdb.com/name/nm1141070/?ref =fn al nm 1; Nacho Vigalondo: http://www.imdb.com/name/nm1443023/?ref =nv sr 1 Fecha de consulta 1 de Junio de $\underline{2016}$

${ }^{8}$ Informes "Cifras y Letras del Cortometraje en la Comunidad de Madrid" a cargo de Carlos Medina entre 2008-2011. 
elegido como población objeto de estudio a los guionistas y directores como creadores de cortometrajes es porque, según estos mismos informes, en un $97 \%$ de los casos el guion y la dirección corresponden a la misma persona. De estos datos podemos deducir que los directores y guionistas acaban convirtiéndose en una especie de "hombre orquesta" que realiza las tareas más importantes en la creación de un cortometraje. De ahí el término "creadores" que emplearemos a partir de ahora.

Para delimitar la población objeto de estudio hemos tomado como referencia las listas de largometrajes españoles estrenados en España entre 2011 y 20149. A nivel de cortometrajes solo hemos tenido en cuenta a aquellos que hayan realizado un cortometraje en los últimos dos años. Consideramos este periodo de tiempo ya que es el "tiempo de vida" medio de un cortometraje. La mayoría de los festivales de cine que, como hemos visto, son el "habitat natural" de los cortometrajes, ofrecen la posibilidad de presentar cortometrajes producidos hasta dos años antes de la realización del propio festival, así es en la mayoría de los festivales tanto nacionales como internacionales según la base de datos de Promofest ${ }^{10}$. Es decir, en líneas generales estos creadores elegidos son cortometrajistas en activo.

Para la selección de la muestra se ha consultado la base de datos del Ministerio de Educación, Cultura y Deporte entre 2012 y 2015 de largometrajes estrenados y comparado con la base de datos Internet Movie Data Base (IMDB en adelante) para reducir la muestra a los directores o guionistas con película estrenada en los últimos años y que, además, hayan realizado un cortometraje en los últimos dos años (2013-2015). Se ha tenido que recurrir a una base de datos privada como IMDB ante la falta de una base de datos oficial con los directores de largometrajes y cortometrajes. La base de datos del Ministerio sobre los cortometrajes solo tiene en cuenta

\footnotetext{
9 http://www.mecd.gob.es/cultura-mecd/areas-cultura/cine/mc/ace/portada.html Fecha de consulta: 1 de Junio de 2017

${ }^{10}$ La base de datos se puede encontrar en https://www.filmfestivalsdeadlines.com/ con más de 9100 festivales de cortometrajes.

Fecha de consulta: 1 de Junio de 2017.
} 
aquellos con ayudas oficiales y no los miles de cortometrajes que se realizan fuera de la oficialidad en España cada año.

Además del objetivo general previamente planteado, se pretende conocer una serie de objetivos específicos que surgen a partir de este, como son:

1. Conocer los motivos que llevan a estos "creadores" a realizar cortometrajes, siendo muy complicado recuperar comercialmente la inversión económica y de que no necesiten el reconocimiento que a priori podrían dar los cortometrajes.

2. Conocer cómo ha variado su percepción de los cortometrajes con la experiencia en largometrajes.

3. Descubrir la situación actual del cortometraje desde el punto de vista de estos creadores a nivel tanto industrial como creativo.

4. Descubrir las características básicas que, según los creadores, diferencian a los cortometrajes de los largometrajes como forma de expresión única.

Para llevar a cabo la investigación nos hemos decidido por la entrevista en profundidad. Debido a la falta de estudios previos sobre percepción y cortometraje y sobre la percepción del cine en general, nos vemos obligados a emplear un acercamiento interpretativo al objeto de estudio. Esto no quiere decir que los planteamientos sean vagos al respecto, sino que debemos acercarnos al fenómeno con una herramienta que nos permita comprender el contexto y la situación actual que viven los creadores de cortometrajes a partir del análisis de sus discursos (Taylor y Bogdan, 1987). Este estudio cualitativo debe servir para un primer acercamiento que sirva para identificar las cuestiones clave (Blaxter, Hughes y Tight, 2000) que puedan influir en investigaciones futuras. Es importante conocer la experiencia de estos profesionales ya que provee al investigador de una fuente directa de datos (Becker y Geer, 1957) que de otra manera no podrían obtenerse.

Debido también a la reducida población objeto de estudio, ya que hay una gran escasez de creadores que se dediquen al mundo del cortometraje 
habiendo ya trabajado en largometrajes, nos hemos decidido por entrevistar a seis creadores. Se mantendrá el anonimato de los entrevistados para garantizar que sus respuestas no estén condicionadas por una posible repercusión pública. Así pues, cada uno de los entrevistados recibirá un código (E1, E2, E3, E4, E5 y E6). Todos los entrevistados son guionistas y directores, es decir, son los máximos responsables artísticos de sus obras. E1 es un guionista y director que ha escrito 3 largometrajes en los últimos 8 años y dirigido múltiples cortometrajes desde entonces. E2 es uno de los guionistas y directores con mayor éxito comercial en España. Ha ido encadenando proyectos de largometraje y cortometraje desde que comenzó hace 15 años, su trayectoria como cortometrajista ha sido una de las más premiadas. E3 comenzó como guionista de televisión hace más de 10 años y su éxito profesional le llevó a su primer proyecto en un largometraje como productor y otro como guionista, ha sido además el director de varios cortometrajes de éxito internacional. $\mathrm{E} 4$ ha ganado varios premios en festivales importantes como el de Gijón con su primer largometraje y realizado otro más pendiente de estreno. $\mathrm{E}_{5}$ ha realizado 3 largometrajes y ha ido entremezclando esos proyectos con otros de cortometraje y E6 ha escrito y dirigido 2 largometrajes estrenados comercialmente y sus últimos proyectos hasta 2017 han sido varios cortometrajes.

Las entrevistas han sido registradas y transcritas para su posterior análisis, cuyos resultados expondremos en el siguiente epígrafe. La modalidad de entrevista será semiestructurada. Esto se debe a que pretendemos conocer la percepción que tienen estos creadores, por lo que un bloque cerrado de preguntas podría limitar el espectro de conocimiento. Seguir una modalidad semiestructurada nos permite combinar la dimensión interpretativa de un análisis en profundidad con la posibilidad de establecer marcos de comparación comunes a los diferentes sujetos entrevistados a partir de bloques temáticos comunes, escogidos conforme a los objetivos de investigación, tal y como recogemos en la tabla F1. 


\begin{tabular}{|c|c|c|}
\hline $\begin{array}{l}\text { BLOQUE } \\
\text { TEMÁTICO }\end{array}$ & TEMAS A DESARROLLAR & OBJETIVOS RELACIONADOS \\
\hline 0. Perfil & $\begin{array}{l}\text { - Formación previa. } \\
\text { - Años de experiencia. } \\
\text { - Proyectos previos y actuales en cortometrajes y } \\
\text { largometrajes. }\end{array}$ & Identificar la trayectoria del entrevistado. \\
\hline 1. Motivaciones & $\begin{array}{l}\text { - Motivaciones iniciales en la realización de } \\
\text { primeros cortometrajes. } \\
\text { ¿Qué te llevó a realizar cortometrajes en } \\
\text { un primer momento? } \\
\text { - Motivaciones actuales en la realización de } \\
\text { cortometrajes. } \\
\text { ¿Por qué en la actualidad realizas/has } \\
\text { realizado/sigues realizando cortometrajes? }\end{array}$ & $\begin{array}{l}\text { Conocer motivos y motivaciones para la } \\
\text { realización de cortometrajes. }\end{array}$ \\
\hline $\begin{array}{l}\text { 2. La experiencia } \\
\text { del creador }\end{array}$ & $\begin{array}{l}\text { - Medios materiales y económicos. } \\
\text { - Comparación con experiencia en largometrajes. } \\
\text { - Otras dificultades y retos. }\end{array}$ & $\begin{array}{l}\text { Conocer la percepción profesional acerca } \\
\text { de cortometrajes. }\end{array}$ \\
\hline $\begin{array}{l}\text { 3. El cortometraje } \\
\text { en España }\end{array}$ & $\begin{array}{l}\text { - Apoyo institucional. } \\
\text { - Situación de la industria. } \\
\text { - Redes y plataformas de } \\
\text { colaboración/difusión/distribución. } \\
\text { - Comparación de la situación con el largometraje. }\end{array}$ & $\begin{array}{l}\text { Conocer las valoraciones acerca de la } \\
\text { situación de los cortometrajes. }\end{array}$ \\
\hline $\begin{array}{l}\text { 4. La creación del } \\
\text { cortometraje }\end{array}$ & $\begin{array}{l}\text { - Creación. } \\
\text { - Narrativas. } \\
\text { - Rodaje. } \\
\text { - Equipos técnicos y artísticos. }\end{array}$ & $\begin{array}{l}\text { Conocer las valoraciones acerca de } \\
\text { procesos creativos. }\end{array}$ \\
\hline
\end{tabular}

F1. Fuente: Elaboración propia.

En primer lugar, solicitamos a los creadores una aproximación personal a su carrera profesional a fin de conocer de primera mano cómo fueron sus años formativos en la industria cinematográfica.

Analizaremos en el Bloque 1 las cuestiones relacionadas con el primer objetivo de la investigación: cuáles fueron las motivaciones iniciales para realizar cortometrajes y cuáles son ahora para seguir realizándolos, una práctica poco habitual una vez se alcanza un estatus dentro del universo cinematográfico español, tal y como presentamos en nuestra introducción. Es decir, cómo ha evolucionado su perspectiva de los cortometrajes con el tiempo y la experiencia.

En el Bloque 2 queremos que los autores den su punto de vista sobre las cuestiones que tiene que ver con el cortometraje en relación al largometraje, sus similitudes y diferencias y cómo se desarrollan unos y otros según su propia experiencia. 
Posteriormente en el Bloque 3 queremos resolver el tercer objetivo de investigación: conocer la perspectiva de los creadores sobre el cortometraje en el contexto actual del país, tanto a nivel comercial, de exhibición, de financiación y de explotación. La experiencia en los ámbitos tanto del cortometraje como del largometraje puede servir para conocer la situación particular que viven los creadores a la hora de afrontar unos proyectos y otros.

Para finalizar, con el Bloque 4 pretendemos que los creadores ayuden a identificar los procesos de creación y cómo se producen en el mundo del largometraje y en el del cortometraje, resolviendo así el último objetivo de investigación, las características básicas del cortometraje a nivel creativo.

A pesar de la disposición en bloques el carácter semiestructurado de la entrevista nos ha llevado a alejarnos de un proceso cerrado y a tener la flexibilidad necesaria para poder profundizar en todos los temas y responder así a los objetivos de la investigación.

\section{Exposición y conclusiones}

\subsection{La pulsión de rodar}

Las entrevistas en profundidad con estos tres creadores cinematográficos nos han servido para conocer las motivaciones de estos creadores al afrontar la realización de un cortometraje. Algunos de los motivos han cambiado desde sus primeras experiencias, normalmente universitarias, y las actuales, ya pertenecientes a la industria del cine, pero otros se mantienen desde sus inicios. Es decir, se ha producido una evolución clara en su percepción de los cortometrajes, de lo que suponen en sus carreras y de lo que supone la industria del cortometraje en España.

Tampoco distinguía mucho yo en esa época la cosa entre los largos y los cortos, es decir, que para mí era hacer películas y punto. Sí que es verdad que luego adquieres más consciencia y ves que el corto tiene mucho de práctica y de salto al largo (E2). 
Hay que destacar que, dado que sus experiencias iniciáticas las realizaron en el transcurso universitario, es lógico pues que para ellos supusiera una manera de practicar el oficio cinematográfico. Como mencionamos previamente parece que los creadores eran conscientes también de que la realización de cortometrajes se convierte para los aspirantes a directores de largometrajes en un paso necesario en sus carreras (Barroso, 1996; Delgado, 2003) bien como tarjeta de presentación o bien como herramienta de aprendizaje. Es más, ellos mismos han pasado por ese primer proceso de realizar cortometrajes para practicar, para abrirse paso en la industria, o simplemente para probar si realmente les atraía la idea de contar historias con una cámara.

Estos dos elementos: "práctica" y "salto al largo" parecen definir un "camino natural" que es el que siguen los directores en sus carreras. Parece, pues, haber un proceso que hay que seguir en la industria, que existen diferencias significativas entre realizar cortometrajes y largometrajes y que estos últimos gozan de una categoría más elevada frente a los primeros. Sin embargo estos creadores matizan:

Es verdad que en lo últimos años ha habido como un corte, que de igual manera que gente de mi generación saltó al largo de manera muy fácil porque era el camino normal, (...) en los últimos siete años es algo que está costando bastante más (E2).

O como apostilla E1:

No es necesariamente un trampolín hacia el largo.

Queda en entredicho esa asunción general que tienen los estudiantes de cine de que hay un camino natural hacia la realización de cortometrajes. De hecho, desde el año 2000 sólo siete de todos los directores que han ganado un premio Goya en la categoría de Mejor Cortometraje (lo que cabría suponer un logro mayúsculo y suficiente para demostrar su valía como creadores) han realizado un largometraje posteriormente, dos de ellos ya habían realizado largometrajes antes y sólo uno, Mateo Gil, ha realizado dos largometrajes ${ }^{11}$

${ }^{11}$ www.premiosgoya.com 
(habría que destacar que directores como Mateo Gil o Daniel Guzmán ya estaban consagrados en el universo cinematográfico nacional antes de recibir el premio). Esto pone de manifiesto que, efectivamente, los cortometrajistas más laureados no siempre consiguen dar ese salto al largometraje.

A pesar de que en sus comienzos la realización de cortometrajes sí podía suponer un lanzamiento o salto al largometraje, ha habido una evolución en su actitud a la hora de afrontar el proceso de realización de un cortometraje. Sin embargo, alcanzado ese éxito profesional parece que pueden volver a explorarlo desde la autonomía del género. El reconocimiento industrial se ha perdido a la hora de sentir una necesidad de realizar obras por el hecho de que sea bueno para sus carreras profesionales:

No hay una voz que me dice, "oye tienes que hacer esto porque va a ser bueno para que te nominen al Goya, no” (E3).

Los autores descreen de esa asunción general, si bien empiezan por dos motivos principales: práctica y búsqueda de reconocimiento. De hecho y como reconoce E6: "La intención era divertirme y luego siempre ha habido un componente importante de querer aprender con el proceso. Aprender y divertirme”. Ahora hay una motivación más grande y compartida por estos creadores: la pulsión de crear.

Lo hago por entretenimiento puro y duro. Porque me gusta rodar, me encanta. Soy un enamorado de rodar y soy un adicto a rodar. Es pura adrenalina. Necesito a veces esas pequeñas descargas de rodar cortos ya casi hasta por deporte. (E4).

Los creadores comparten un elemento en común que les lleva, en primer lugar, a realizar cortometrajes. Esto se podría definir como una pulsión creadora que les lleva a escribir y dirigir sus historias, que surge de una parte muy íntima de su ser y que les lleva a dirigir cortometrajes a pesar de las numerosas dificultades con las que pueden encontrarse porque realmente lo necesitan, no pueden ignorar el instinto creador (Fiorini, 1995). Esto es una constante en todos ellos: Les gusta rodar, les gusta contar historias: "me lo 
paso muy bien" (E1), "a uno le gusta mucho rodar" (E2), "tienes ganas de hacer eso" (E5). Es en cierta medida una forma de autorrealización: crear les hace felices (Maslow, 1994).

Todos estos elementos se articulan en torno a esa pulsión por contar historias, que es la motivación que les lleva a hacer cine. ¿Por qué eligen canalizar este ímpetu creador a través de la forma expresiva del cortometraje y no de otra? Los creadores eligen el formato corto frente a la posibilidad de realizar largometrajes o series de televisión y esto se da por varios motivos:

a)- la historia lo pide.

Hay historias que son de corto y punto y merece la pena contarse en ese formato (E2).

De repente hay una historia que es cortita, concreta y te vale para eso (E5).

Hay historias que parecen requerir el formato corto. Existe una creencia compartida por los creadores de que los largometrajes y los cortometrajes aunque mantengan elementos en común son formas expresivas muy diferentes, sobre todo a nivel de historia. Y cómo tales deben ser tratadas y contadas de forma distinta. Así pues, los cortometrajes difieren de los largometrajes como "pueden escribirse relatos cortos o novelas largas” (E1).

b)- La inmediatez.

Es muchísimo más fácil encontrar financiación para un corto porque es más barato (E1).

Todos ellos coinciden en que hacer cortometrajes es más sencillo que hacer largometrajes. La principal razón es la económica. Rodar cortometrajes es mucho más barato que rodar largometrajes. Los días de rodaje son mucho más reducidos y manejables. La realización de largometrajes es una tarea tan grande y titánica que a menudo es una actividad que se realiza cada tres o cuatro años y con un largo rodaje mediante (Furió, 2012), mientras que los cortometrajes se pueden realizar en un fin de semana, y gracias a su reducido costo, mucho más regularmente (Adelman, 2005). Por eso es importante esta función que realiza el cortometraje en la carrera de los creadores consagrados que no es otra que la de contar historias. 
c)- La experimentación.

Yo siempre que he hecho cortos después de hacer largos, ha tenido algo de experimento (E2).

Son experimentos narrativos (E5).

Experimentar en cortometrajes les resulta más sencillo que en largometrajes. Por los elementos antes mencionados (menor responsabilidad comercial, menor duración de rodaje) los creadores sienten que los cortometrajes son perfectos para experimentar: el hecho de ser más baratos y de no tener expectativas comerciales convierte a los cortometrajes en un elemento de experimentación que no tienen en los largometrajes (Adelman, 2005).

\subsection{El eterno problema de la financiación}

A la hora de hablar de la realización de los cortometrajes los autores coinciden en una serie de dificultades a las que tienen que enfrentarse para completar sus obras. Para los creadores hay una dificultad que está por encima de las demás:

El gran problema es el dinero (E5).

Conseguir la financiación es el principal problema a la hora de levantar un proyecto de cortometraje. Al igual que les ocurre con los largometrajes, pero con una dificultad añadida: recuperar el dinero es más difícil en el caso de los cortometrajes debido, tal y como analizamos en la introducción, a la pobre difusión que ofrece el circuito de festivales, su escasa presencia en televisiones y su nula presencia en salas. La falta de rendimiento comercial de los cortometrajes dificulta en gran medida la búsqueda de una financiación privada, dejando las ayudas estatales como la ventana de financiación básica:

Por un lado, debería haber apoyo institucional y por otro lado leyes fiscales que favorezcan la inversión privada. El problema es que el apoyo gubernamental es escaso y las leyes de reforma fiscales que se llevan prometiendo mucho tiempo no existen (E1). 
Los creadores reconocen que han sufrido una evolución a la hora de conseguir financiación para sus proyectos. Si bien sus primeros cortometrajes fueron, en la mayoría de los casos, con poco o inexistente presupuesto, autofinanciados y a base de favores de compañeros y amigos "el cortometrajista es básicamente un gorrón” (E2). La relevancia nacional que ha conseguido que les haya ayudado a la hora de conseguir el dinero necesario para los siguientes proyectos.

El primer corto fue autofinanciado y a raíz de que el primero fuera bien sí que hemos tenido más apoyo, sobre todo del Ministerio de Cultura y de la Comunidad de Madrid en nuestros cortos (E1).

$\mathrm{Su}$ experiencia en largometrajes les otorga un estatus de cara a conseguir dinero público. A pesar de que no existe una base legal según el Ministerio de Cultura por la cual se concedan más ayudas a los creadores más experimentados o más reconocidos ${ }^{12}$, sí parece ser que a medida que los directores han conseguido renombre, ha resultado más fácil conseguir subvenciones públicas. Es más, sus proyectos una vez consagrados en la industria parece que han gozado de presupuestos excepcionales:

Cuando hemos necesitado presupuestos fuertes los hemos tenido (E3).

O según E2:

Si es un corto que tienes bien producido hay veces que yo, si te digo la verdad, muchas veces he tenido más lujos que rodando un largo.

El análisis de las entrevistas deja ver la situación particular que viven los creadores de cortometrajes. Por un lado, el mayor problema para realizar cortometrajes es conseguir la financiación necesaria, pero por otro reconocen que para sus proyectos casi siempre han conseguido una financiación más que generosa por parte del Estado o de los gobiernos autonómicos. Para un director consagrado parece más fácil conseguir las ayudas "subjetivas”, es decir, las que se conceden según criterios artísticos del guion o la trayectoria

${ }^{12}$ Las bases para la concesión de ayudas a cortometraje sobre proyecto se pueden consultar en la web del Ministerio de Educación, Cultura y Deporte: http://www.mecd.gob.es/servicios-al-ciudadano-mecd/catalogo/cultura/becas-ayudas-ysubvenciones/ayudas-y-subvenciones/cine.html

Fecha de consulta: 1 de Junio de 2017 
previa de los creadores (Puertas, 2003). Podría ser este uno de los motivos que les llevan a volver a la realización de cortometrajes, o al menos que facilite su regreso, como expone E3:

Sí hay un porqué muy claro de porqué hago unas historias y no otras, que es que alguien las apoye.

\subsection{El cortometraje en España}

Para los creadores el cortometraje vive una situación muy diferente de la del largometraje en nuestro país y es que:

Aquí no hay una industria del cortometraje, casi no la hay del largometraje, mucho menos del cortometraje (E4).

Los creadores coinciden en que, a pesar de las iniciativas de la creación de la Asociación de la Industria del Cortometraje (AIC), la Coordinadora del Corto Español (CCE) o la Plataforma de Nuevos Realizadores (PNR) ${ }^{13}$, no existe una industria del cortometraje. La falta de una industria estable conlleva pareja una falta de profesionalización en los miembros de los equipos técnicos de los cortometrajes porque "existe la premisa general de que la gente no cobra, de que los actores no cobran, de que un corto no está hecho para ganar dinero" (E2). Esto repercute en la calidad técnica de los cortometrajes: la mayoría de los creadores reconoce que en un momento $\mathrm{u}$ otro al comienzo de sus carreras han tenido problemas técnicos importantes por la falta de una financiación adecuada. Entre los años 2010 y 2017 las ayudas sobre proyecto a los cortometrajes se han reducido hasta un 50\% de un millón de euros hasta los 500.000 que se conceden en $2015^{14}$. Estas ayudas sitúan a España por detrás de otros países europeos como Francia (Izquierdo, 2012) que mantiene una gran cantidad de ayudas al cine con su “excepción cultural” (Arizpe y Alonso, 2005; Izquierdo, 2009). Sin embargo, según E4:

13 AIC: http://www.aicortometraje.es/

PNR: http://www.plataformanuevosrealizadores.com/

CCE: http://coordinadoradelcorto.org/

${ }_{14}$ Estos datos se pueden consultar en la web del Ministerio de Educación, Cultura y Deporte: http://www.mecd.gob.es/servicios-al-ciudadano-mecd/catalogo/cultura/becas-ayudas-ysubvenciones/ayudas-y-subvenciones/cine.html

Fecha de consulta: 1 de Junio de 2016. 
A nivel formal no existen grandes diferencias entre los cortometrajes españoles y los de fuera.

La falta de ayudas repercute sobre la profesionalización de la inexistente industria del cortometraje español, pero según estos entrevistados, no supone una diferencia significativa de calidad. Esta diferencia cualitativa tiene más que ver con el talento y el oficio de los creadores de otros países que con los presupuestos; son diferencias mucho más arraigadas culturalmente que no pueden subsanarse con el dinero. Es posible que otros países como Francia o Estados Unidos con "una sólida tradición cinematográfica" (Gubern, 2014) y una producción industrial mayor (Izquierdo, 2012) tengan una ventaja sustancial a la hora de hacer cine sobre otros países.

Sin embargo, no existe una postura clara respecto a la financiación pública y sí una amplia división de opiniones.

Sí, creo que el apoyo debe ser de las instituciones. (...) El cine es una industria cultural y como cultura debe ser protegida (E1)

Si justamente yo creo que en España es dónde los cortos tienen más presupuesto (E2).

La diferencia de presupuestos con, por ejemplo, Estados Unidos, es abismal (E4).

Todos consideran que la financiación pública es necesaria para crear y fomentar una industria del cortometraje, pero, por un lado, mientras que algunos consideran que la financiación actual es suficiente, otros abogan por aumentarla. Atendiendo al perfil de los entrevistados descubrimos que los que tienen un perfil de éxito mayor a nivel económico (ya sea en cortometrajes, largometrajes o televisión) creen que el sistema está bien mientras que el creador con un perfil de creación más “independiente" aboga por la defensa de una subvención pública fuerte. Estos supuestos mantienen vivo el eterno debate entre un cine que pueda sobrevivir por la ayuda necesaria de las subvenciones públicas o que el cine sea menos dependiente del Estado como en otros países europeos (Puertas, 2003; Felici \& Campillo, 
2006) y con una inversión menor (Lipovetsky y Serroy, 2009). En definitiva, no hay un consenso para estos creadores sobre el presente y el futuro del cortometraje español y las subvenciones públicas.

Respecto a la distribución de los cortometrajes, estos creadores apoyan la teoría de que los festivales de cine son la plataforma mayoritaria de los cortometrajes en España. Los cortometrajes se hacen para los festivales porque su proyección en salas es inexistente y en televisión es mínima:

No, de las televisiones no hay nada. Los únicos que dan apoyo en televisión es Movistar + que compra, aunque cada vez compra menos (E2).

Se investigó si el futuro de los cortometrajes podría pasar por su reposición en las salas comerciales de cine (como ocurría en los años posteriores al NODO) o en las televisiones, como abogan algunos teóricos (Fernández, 2015). Sin embargo, los creadores defienden la libertad de elección tanto de salas como de televisiones:

No se puede exigir a la televisión privada que ponga cortos porque es una empresa privada (E1).

En general los entrevistados no consideran que haya que imponer la programación de cortometrajes en ninguna plataforma, ni en los cines ni en la televisión. Para estos creadores el futuro de los cortometrajes se encuentra en los festivales de cine (que es también su presente) y en internet. Incluso se atreven a señalar que el propio cine se dejará de emitir en salas y también tiene que buscar una distribución futura alternativa:

Parece un poco absurdo demandar que los cortos se exhiban en salas cuando prácticamente los largos van a dejar de exhibirse en salas en algún momento. Estamos ante una nueva realidad y hay que ver cómo se encaja ahí, pero para mí no pasaría por las salas. Ahora mismo el papel más importante sigue siendo el de los festivales (E1).

La solución parece pasar por Internet como elemento de comunicación de masas en el que sea más fácil encontrar los nichos de audiencias (Álvarez et al., 2007) y en el que la ventaja significativa sea la comunicación directa, sin una intermediación de la industria (López, 2005), al igual que ocurre con los 
largometrajes, o incluso las series de televisión, y a un menor coste (Gavilán, Vaquer y Drake, 2014). Este sistema en los márgenes de la industria hegemónica, más barato y más rápido parece que tiene mucho que ver con ese espíritu independiente del cortometraje. Mientras tanto, los cortometrajes se hacen sobre todo para los festivales, lo que entronca con la idiosincrasia propia de los festivales y condiciona la creación de los cortometrajes: su carácter competitivo. Si los cortometrajes se hacen para los festivales de cine y estos tienen como finalidad elegir los mejores cortometrajes para premiarlos, es una posibilidad muy real que los cortometrajes se hagan pensando por y para los premios y no por y para los espectadores. De hecho, los autores a la hora de hablar de sus propios cortos o de otros con los que han competido hablan del éxito o la ausencia del mismo en función de los premios recibidos. Los premios de los festivales se convierten en la principal fuente de remuneración para los autores. Es decir, los premios son dinero y este se convierte en la única herramienta para medir el éxito de un corto. Mientras que los largometrajes tienen la taquilla, los festivales o la crítica especializada para poder medir de una forma externa su éxito, los cortos sólo parecen tener los premios en festivales como herramienta para medir el éxito de su propia obra. Así pues, los autores hablan de los cortometrajes más por el éxito que hayan cosechado en festivales que por el valor artístico intrínseco de la propia creación.

Hablamos de un formato en el que no hay prácticamente beneficio industrial salvo en el hipotético caso de que una vez distribuido el cortometraje triunfe en el circuito de festivales (E3).

\subsection{Aspectos creativos}

Como hemos visto en la revisión teórica, la creación de cortometrajes y largometrajes a nivel de narración y creativo no son iguales, aunque comparten características básicas. A la hora de hablar de la creación de un cortometraje y un largometraje los autores recalcan que no hay grandes diferencias en el rodaje y la postproducción, a excepción del propio tiempo de cada proceso, que es más largo en el largometraje como cabría esperar, pero sí en el proceso de escritura. En general los procesos de escritura de un 
cortometraje y un largometraje son completamente diferentes, aunque matizan: está el proceso interno del creador, que es diferente en cada persona y en cada caso: "cada uno escribe de una manera y el proceso creativo es siempre diferente incluso dentro de la misma persona. Yo no sigo el mismo proceso escribiendo un largo, que escribiendo un corto o que escribiendo otra película" (E1). Aunque todos coinciden en un punto común entre cortometraje y largometraje y es que el tiempo empleado en uno y otro son muy diferentes:

El proceso de escribir o dirigir una película a lo mejor es un año o dos años de trabajo en el que pasas por muchos sitios. El corto a lo mejor estoy dos meses escribiendo, pero nunca estás un año" (E1) "Un corto lo puedes escribir de una sentada y un largo no (E6).

Otra de las grandes diferencias creativas entre uno y otro se debe a que el número de tramas y personajes se ve radicalmente reducido en el cortometraje: "creo que el largometraje suele implicar más multiplicidad de puntos de vista, muchas más situaciones" (E3). Esto se debe principalmente a la duración de uno u otro. Nos referimos a la duración de la obra en sí y no solo al proceso de escritura. En el largometraje hay que mantener el interés del espectador en el caso del largometraje mucho más tiempo, lo que entraña una dificultad extra:

eso que decían que el corto tiene mérito, o más mérito, porque hay que ser capaz de condensar, vi que era mentira. Lo difícil no es condensar, lo difícil es mantener el interés durante 90 minutos" (E2). "A la hora de gestionar la atención del espectador en un corto... es más fácil, no es lo mismo pensar que estás en el minuto 2 que en el minuto 30 (E6).

Esta idea compartida por los creadores entra en contradicción con la teoría de un tótem del guion como es Chion cuando dice que la reducción de tiempo y páginas necesita de una gran concentración y es que "el arte de los grandes guionistas y los grandes cineastas es un arte de la concentración, de la simplificación y de la reducción a lo esencial” (Chion, 1988, p.80)

Respecto a la libertad creativa del cortometraje frente al largometraje, todos los autores coinciden es que es una de las mayores virtudes del corto frente al 
largo. Esto se debe sobre todo a dos elementos. Por un lado la diferencia de presupuesto entre uno y otro y por otro la falta de aspiración comercial de los cortometrajes. Esta idea la resume perfectamente la frase de E1:

Sí. Hay más libertad porque se necesita menos dinero. La libertad normalmente es inversamente proporcional al dinero que uno necesita.

De la presente investigación podemos definir las constantes contradicciones que vive el cine español en general y el del cortometraje en particular. Si bien la calidad del cortometraje español parece fuera de toda no lo es tanto el sistema en el que se desarrolla. Nos parece por tanto fundamental definir con claridad cuáles son los problemas en los que el cortometraje se encuentra sumergido para mejorar todos los aspectos de la producción y por lo tanto dar a nuestro cine la visibilidad que se merece.

\section{Referencias bibliográficas}

Adelman, K. (2005). Cómo se hace un cortometraje. Barcelona: Robinbook.

Álvarez, J. M., Calvi, J. C., Gay, C., Gómez-Escalonilla, G., López, J., de Estudios, M. D. L. G., y Piedras, E. (2007). Alternativas de política cultural: las industrias culturales en las redes digitales (disco, cine, libro, derechos de autor). Barcelona: Gedisa.

Amitrano, A. (1998). El cortometraje en España: una larga historia de ficciones breves. Generalitat Valenciana.

Aristóteles (1974). Poética de Aristóteles. Madrid: Gredos.

Arizpe, L., y Alonso, G. (2001). Cultura, comercio y globalización. En Estudios Latinoamericanos sobre cultura y transformaciones sociales en tiempos de globalización 2. Buenos Aíres: CLACSO.

Barroso J. (1996). Cortometraje en televisión. En Medina, P., González, L. M., y Velázquez, J. M. (Eds). Historia del cortometraje español. Madrid: Festival de Cine de Alcalá de Henares, pp. 257-297.

Becker, H., y Geer, B. (1957). Participant observation and interviewing: A comparison. Human organization. Vol. 16 (3), pp. 28-32.

Belchi, J. T. C. (1996). 1896-1914. Primeros años del cinematógrafo en Madrid. In Primeros tiempos del cinematógrafo en España (pp. 5364). Gijón: Universidad de Oviedo.

Blaxter, L., Hughes, C., y Tight, M. (2000). Cómo se hace una investigación. Barcelona: Gedisa.

Burch, N. (1985). Praxis del cine (Vol. 2). Madrid: Fundamentos. 
Calero, T. (2002). Reflexiones de un guionista. En Años de corto: apuntes sobre el cortometraje español desde los noventa (pp. 33-45). Murcia: Universidad de Murcia.

Chion, M. (1988). Cómo se escribe un guion. Madrid: Cátedra.

Cooper, P. D., Cooper, K. P., y Dancyger, K. (2002). El guión de cortometraje. Madrid: IORTV.

Delgado, Y. (2003). Antología: cortos de cine. Madrid: Santillana. 22

Deltell, L. (2006). El nuevo hombre orquesta: el director de cortometrajes y novel en España. Área Abierta, 14, 1-8.

Espada, M. D. C., Grau, C., y Fortes, M. C. (2010). Enseñar estrategias de afrontamiento a padres de niños con cáncer a través de un cortometraje. Anales del Sistema Sanitario de Navarra (Vol. 33, No. 3, pp. 259-269). Gobierno de Navarra. Departamento de Salud.

Gabelas, J. A. (2010). La creación de un cortometraje: un proceso de mediación en la promoción de la salud del adolescente (Tesis doctoral). Universidad Complutense, Madrid.

Felici, J. M., y Campillo, M. S. (2006). Las ayudas a la producción en el cine norteamericano. notas sobre los mitos del libre mercado en la era de la globalización. Castellón: Universitat Jaume I.

Fernández, E. C. G. (2015). Marca e identidad del cine español: proyección nacional e internacional entre 1980 y 2014. Madrid: Fragua.

Fernández -Sánchez, M. C. (1997). Influencias del montaje en el lenguaje audiovisual. Madrid: Libertarias.

Fiorini, H. J. (1995). El psiquismo creador. Buenos Aires: Paidós.

Furió, D. M. (2012). La producción cinematográfica: las fases de creación de un largometraje. Barcelona: UOC.

García-Santamaría, J. V. (2015). La exhibición cinematográfica en España, Madrid: Cátedra.

Gavilán, J. C., Vaquer, J. R., y Drake, A. T. (2014). Distribución audiovisual en Internet: VoD y nuevos modelos de negocio. Barcelona: UOC.

Gubern, R. (2014). Historia del cine. Barcelona: Anagrama.

Izquierdo Castillo, J. (2012). El fomento del cine europeo y su comercialización. Estudio comparado de los cines español y francés. Icono1, 10, 79-93.

Izquierdo Castillo, J. (2009). Las fuentes de financiación y la competitividad del cine español. En El productor y la producción en la industria cinematográfica. Madrid: Universidad Complutense

Karel, R. (1987). Técnica del montaje cinematográfico. Madrid: Taurus.

La percepción del cine español por el público (2009). Madrid: Egeda. 
Lipovetsky, G., y Serroy, J. (2009). La pantalla global: cultura mediática y cine en la era hipermoderna. Barcelona: Anagrama.

Llínas, F. (1996). El cortometraje en los años 60 y 70. En Medina, P., González, L. M., y Velázquez, J. M. (Eds). Historia del cortometraje español. Madrid: Festival de Cine de Alcalá de Henares (163-165).

López, J. (2009). Teoría del guion cinematográfico: Lectura y escritura. Madrid: Síntesis

López García, G. (2005). El ecosistema digital: Modelos de comunicación, nuevos medios y público en Internet. Valencia: Servei de Publicacions de la Universitat de València.

Maslow, A. H. (1994). La personalidad creadora. Barcelona: Kairós. 23

Medina, P., González, L. M., y Velázquez, J. M. (1996). Historia del cortometraje español. Madrid: Festival de Cine de Alcalá de Henares.

Meier, A. (2013). El cortometraje: el arte de narrar, emocionar y significar. Ciudad de México: Universidad Autónoma Metropolitana.

Ontoria, M. (2007). El uso del cortometraje en la enseñanza de ELE. RedEle , Febrero, 1-11.

Puertas, E. D. (2003). Historia social del cine en España. Madrid: Fundamentos.

Sánchez-Escalonilla, A. (2001). Estrategias de guión cinematográfico. Barcelona: Ariel.

Schwartz, H. J. J. (1984). Sociología cualitativa: Método para la reconstrucción de la realidad. México: Trillas.

Taylor, S. J., y Bogdan, R. (1987). Introducción a los métodos cualitativos de investigación. Buenos Aires: Paidós.

Taylor, S. J., y Bogdan, R. (2008). La entrevista en profundidad. En Métodos cuantitativos aplicados 2. Chihuahua: CID.

Tranche, R. R. (1996). El cortometraje durante el franquismo. En Medina, P., González, L. M., y Velázquez, J. M. (Eds). Historia del cortometraje español. Madrid: Festival de Cine de Alcalá de Henares (79-93).

Vale, E., y Wald, M. (1989). Técnicas del guión para cine y televisión. Barcelona: Gedisa.

Velázquez, J. M., y Ramírez, L. A. (2000). Una década prodigiosa: el cortometraje español de los noventa. Madrid: Festival de Cine de Alcalá de Henares.

Yáñez, J. (2010). La medida de los tiempos: El cortometraje español en la década de 200o. Madrid: Festival de Cine de Alcalá de Henares. 